\title{
DNA methylation: a marker for carcinogen exposure and cancer risk
}

\author{
Takeshi Nakajima $\cdot$ Shotaro Enomoto $\cdot$ \\ Toshikazu Ushijima
}

Received: 17 July 2007/Accepted: 24 August 2007/Published online: 11 December 2007

(C) The Japanese Society for Hygiene 2008

\begin{abstract}
Cancers arise as a consequence of multiple genetic and epigenetic alterations. Many genes aberrantly methylated in cancers have been identified in recent years, and their use in cancer diagnosis and therapy is currently under investigation. During our genome-wide screening for a novel tumor-suppressor gene in gastric cancers, we found that only a small amount of aberrant methylation was present, even in non-cancerous gastric mucosae. A subsequent large-scale analysis of the gastric mucosae of healthy individuals and gastric cancer patients using quantitative methylation-specific PCR (qMSP) revealed that Helicobacter pylori infection potently induced aberrant DNA methylation in non-cancerous gastric mucosae and that these high methylation levels can decrease following cessation of the H. pylori infection. Helicobacter pylori infection induced the methylation of specific genes among 48 genes that can be methylated in gastric cancer cell lines. Most importantly, the methylation levels in the gastric mucosae of individuals without $H$. pylori infection correlated with their risk of gastric cancer. These findings show that a field for cancerization is formed by $H$. pylori infection and that this field can be measured using DNA methylation as a marker. The concept of an "epigenetic field for cancerization" has been also demonstrated for colon and breast cancers, and it is possibly present for other cancers and other diseases. Applied knowledge of epigenetic changes in
\end{abstract}

T. Nakajima $\cdot$ S. Enomoto $\cdot$ T. Ushijima $(\bowtie)$

Carcinogenesis Division,

National Cancer Center Research Institute,

5-1-1 Tsukiji, Chuo-ku, Tokyo 104-0045, Japan

e-mail: tushijim@ncc.go.jp

T. Nakajima

Endoscopy Division, National Cancer Center Hospital,

5-1-1 Tsukiji, Chuo-ku, Tokyo 104-0045, Japan human diseases has now started to make an impact on the prevention, diagnostics, and therapeutics of these diseases.

Keywords Cancer - DNA methylation - Epigenetic . Field cancerization · Field defect · Gastric cancer . Helicobacter pylori

\section{Introduction}

Epigenetic modifications are defined as DNA-associated modifications that are faithfully inherited upon somatic cell division, such as DNA methylation at $\mathrm{CpG}$ sites, histone modifications, and polycomb complex formation [1]. DNA methylation, in particular, is faithfully replicated upon cell division [2,3], and is known to serve as a machinery for cellular memory [4]. At the same time, epigenetic modifications show plasticity during development, adaptation, and diseases. Epigenetic modifications are reprogrammed during the formation of germ cells, and dynamic and coordinated changes take place during development and differentiation [5]. Epigenetic changes are also physiologically induced in somatic cells to maintain the memory of exposure to environmental stimuli $[6,7]$.

Our increasing knowledge of epigenetic changes in human diseases has now started to make an impact on the prevention, diagnostics, and therapeutics of these diseases. From a viewpoint of environmental health and preventive medicine, epigenetic alterations in non-disease tissues are becoming important because it is becoming clear that they can be used as markers for disease risk and past exposure to some disease-inducing factors. In this review, we provide a brief introduction to aberrant DNA methylation in cancers, describe our experimental findings on the presence of aberrant DNA methylation in non-cancerous gastric 
mucosae, including a description of its use as a marker for both the risk of gastric cancers and past exposure to Helicobacter pylori, an established gastric carcinogen and, finally, discuss the concept of field cancerization and its usefulness an a diagnostic marker in other cancers.

\section{Aberrant DNA methylation in cancers}

\section{Aberrant DNA methylation in carcinogenesis}

The existence of aberrant DNA methylation in cancer tissues has been known since the early 1980s, but it was not until the early 1990s that it was shown to have a causal involvement in human cancers [1, 8]. Aberrant DNA methylation in cancers is often summarized as (1) genomeoverall hypomethylation and (2) regional hypermethylation. Genome-overall hypomethylation is mainly due to hypomethylation of repetitive DNA sequences, such as LINE and Alu (SINE), that constitute a major part of the genome and are normally methylated [9]. Such hypomethylation can cause chromosomal instability and, consequently, tumors [10] as well as aberrant expression of normally methylated genes, such as melanoma antigen genes (MAGEs) [11]. The aberrant activation of oncogenes due to promoter demethylation (hypomethylation) has as yet not been established.

Regional hypermethylation refers to the aberrant methylation of normally unmethylated sequences, most of which are clusters of $\mathrm{CpG}$ sites, denoted $\mathrm{CpG}$ islands (CGIs). Importantly, when a CGI is located in a gene promoter region, its methylation consistently leads to transcriptional silencing of its downstream gene (Fig. 1). This also applies to many tumor-suppressor genes, such as $C D K N 2 A$ (various cancers), $C D H 1$ (gastric cancers), $A P C$ (colorectal cancers), and BRCAl (breast cancer). Methylation-silencing of tumor-suppressor genes is now known to be involved in various human cancers [1]. In addition to aberrant DNA methylation being causally involved in carcinogenesis (driver methylation), recent genome-wide studies have revealed the presence of many genes whose methylation is considered to be a consequence of carcinogenesis (passenger methylation) [12-14]. This fact clearly demonstrates the need to carefully analyze the role of any newly detected gene in terms of its role in carcinogenesis.

\section{Clinical use of aberrant DNA methylation}

Both diagnostic and therapeutic applications of aberrant DNA methylation in cancers are being developed [15]. One diagnostic application is the use of cancer-specific patterns of aberrant DNA methylation to detect cancer cells and cancer-derived DNA. Different from mutations, aberrant DNA methylation can be detected with high sensitivity -

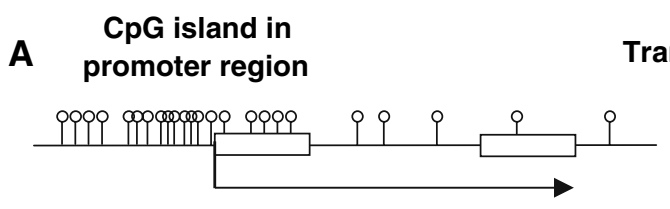

Transcription

B

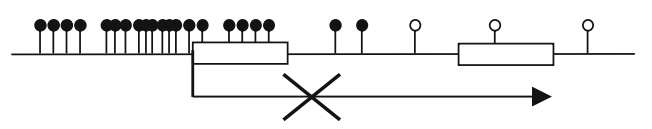

$(-)$

Fig. 1 Methylation of a promoter $\mathrm{CpG}$ island $(C G I)$ and transcription of its downstream gene. Open and closed circles Unmethylated and methylated $\mathrm{CpG}$ sites, respectively. a In a normal cell, most $\mathrm{CpG}$ sites within a promoter CGI are unmethylated. b Methylation of most $\mathrm{CpG}$ sites (dense methylation) of the promoter CGI completely blocks transcription. If such methylation occurs in a tumor-suppressor gene, it leads to inactivation of the tumor-suppressor gene

for example, at a sensitivity of one aberrantly methylated DNA molecule among 1000 molecules. The chemical stability of DNA is also an advantage in this application. A second diagnostic application is the association of patterns of aberrant DNA methylation in cancer tissues with tumor characteristics, such as histological type, risk of disease progression, sensitivity to chemotherapy, and molecular alterations $[15,16]$. An example of this can be found in neuroblastomas, where the methylation pattern is very closely associated with survival risk [17]. Thirdly, methylation in non-cancerous tissues is now recognized as a marker for cancer risk and exposure to carcinogenic factors, which will be the main topic of this review.

In terms of therapeutic purposes, epigenetic abnormalities are now used as promising targets. The Federal Drug Agency has approved two demethylating agents, 5-azacytidine (5-aza; Vidaza) and 5-aza-2'-deoxycytidine (5aza-dC; Decitabine), for hematological malignancies [18]. In addition, preclinical trials are ongoing for solid tumors. Demethylating agents currently seem to have therapeutic windows, being active in tumor cells but having few sideeffects in normal cells. The concept of "maximum tolerance dose" is not valid for demethylating agents, and an optimal dose for maximum demethylating activity should be achieved [18]. Further investigations are necessary on the most suitable dosing, including the identification of appropriate marker genes and tissue, and on the target specificity in cancer and normal cells.

\section{Aberrant methylation in non-cancerous gastric mucosae}

Presence of "aberrant" DNA methylation in non-cancerous gastric mucosae

In human gastric cancers, $C D K N 2 A$ (p16), $C D H 1$ (E-cadherin), and $h M L H I$ are inactivated more frequently by the 
aberrant methylation of promoter CGI than by mutations or chromosomal losses [19]. During previous study carried out in our laboratory in which we identified a novel tumorsuppressor gene, $L O X$ [20], we observed that aberrant DNA methylation was present even in non-cancerous gastric mucosae of gastric cancer patients, although at a very low level [21, 9]. It is unlikely that these cancer cells contaminated non-cancerous samples because aberrant methylation in non-cancerous gastric mucosae was observed too often to be contamination.

Methylation in non-cancerous gastric mucosae and $H$. pylori infection

To clarify the meaning of "a small amount" of aberrant methylation in non-cancerous gastric mucosae, we quantified the methylation levels in gastric mucosae of healthy volunteers and in non-cancerous gastric mucosae of gastric cancer patients [22]. Healthy volunteers (individuals without gastric cancer) and gastric cancer patients were classified according to their status of $H$. pylori infection, a major etiological factor for gastric cancers [23, 24], at the time of sampling. The numbers of methylated and unmethylated DNA molecules were counted, using quantitative methylation-specific PCR (qMSP), for eight regions of seven genes, all of which can be methylated in gastric cancers. Methylation levels were calculated as the number of methylated molecules present among the total number of DNA molecules. This value was considered to represent the fraction of cells with methylation in a gastric mucosa.

All of the eight regions showed a similar tendency in terms of methylation levels. Among healthy volunteers, methylation levels were 5.4- to 303-fold higher in $H$. pylori-positive individuals than $H$. pylori-negative individuals [22]. This finding strongly indicates that H. pylori infection can potently induce aberrant DNA methylation in non-cancerous gastric mucosae. In addition, H. pylori-positive individuals had higher methylation levels than $H$. pylori-negative gastric cancer cases, most of whom were considered to have had prior exposure to H. pylori infection (Fig. 2a).

Temporary and permanent components of methylation level induced by $H$. pylori

The above results indicate that high methylation levels will decrease to certain levels after cessation of the $H$. pylori infection. Since endogenous DNA demethylase has not been established and active demethylation in a cell was unlikely to take place, this decrease is considered to be passive demethylation due to cell turnover. A gastric gland consists of one stem cell, multiple progenitor cells, and many differentiated cells [25], and it is expected that methylation in stem cells will persist forever (permanent component) while methylation in progenitor and differentiated cells will disappear (temporary component). It is therefore likely that $H$. pylori infection induced both permanent and temporary components of methylation, and that

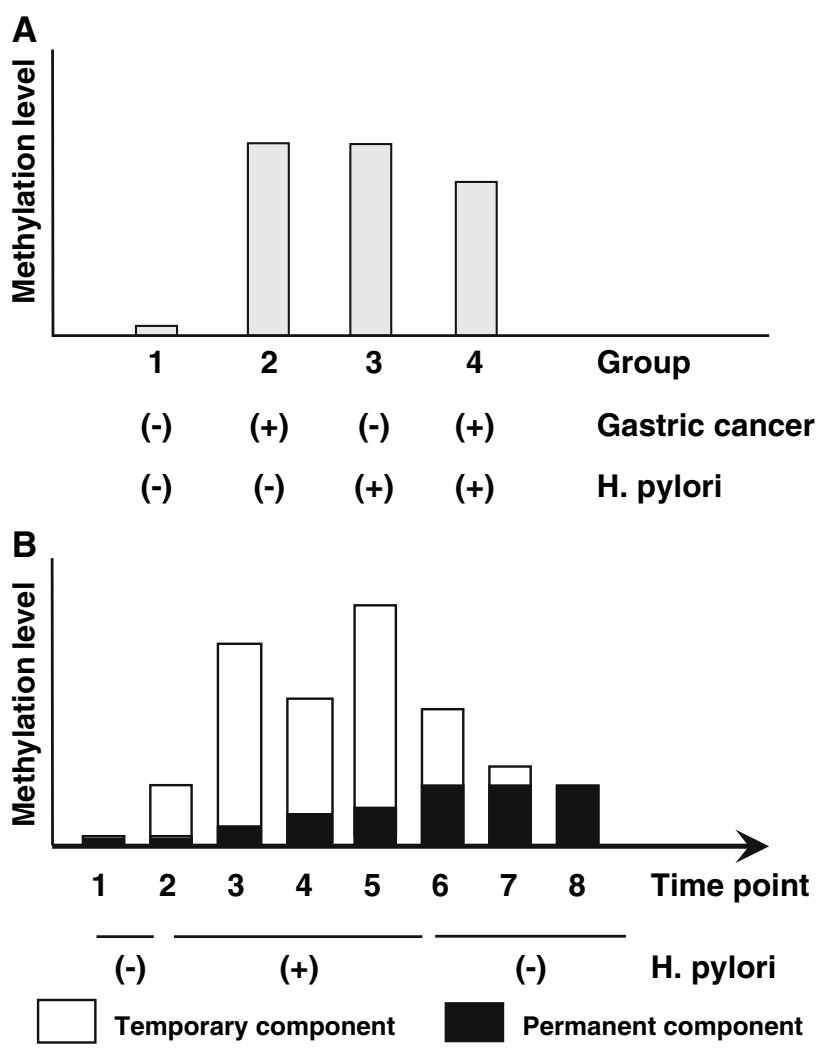

Fig. 2 Methylation induction by Helicobacter pylori infection and gastric cancer risk. a Schematic representation of methylation levels in the gastric mucosae of individuals with and without gastric cancer, and with and without $H$. pylori infection. Methylation levels were measured in DNA extracted from gastric biopsy specimens. Without H. pylori infection, there is a significant difference between healthy volunteers (group 1) and gastric cancer cases (group 2). With $H$. pylori infection, the methylation level is high in both healthy volunteers (group 3) and gastric cancer cases (group 4). H. pyloripositive individuals had higher methylation levels than $H$. pylorinegative gastric cancer cases, most of whom were considered to have had prior exposure to $H$. pylori infection. Modified from Maekita et al. [22]. b A hypothetical temporal profile of gastric methylation levels during the course of $H$. pylori infection in years to decades. Time point 1: Without $H$. pylori infection, the methylation is initially. Time points: $2-5, H$. pylori infection induces both permanent (closed box) and temporary (open box) components of methylation, and the total methylation level fluctuates due to fluctuation of the temporary component. Time points 6-8: after $H$. pylori infection discontinues, the temporary component disappears, and the increase in the permanent component stops. It is speculated that the permanent component is due to methylation in stem cells and that the temporary component is due to methylation in progenitor and differentiated cells. The permanent component is correlated with damage in stem cells, and thus with gastric cancer risk 
the temporary component disappeared after cessation of the H. pylori infection (Fig. 2b).

To support this hypothesis, we eradicated H. pylori and measured methylation levels 6 weeks after the eradication. When the eradication was successful, $F L N c$ (filamin C) methylation levels decreased to certain levels. When eradication failed, methylation levels fluctuated, depending upon the individual (Nakajima, in preparation). The decreased methylation levels in individuals following successful eradication of $H$. pylori was considered to be due to disappearance of the temporary component, leaving only the permanent component in place.

Methylation levels in gastric mucosae as a marker for gastric cancer risk

In the study described above [22], individuals without $H$. pylori infection, whose methylation levels were considered to reflect the fraction of stem cells with methylation, had methylation levels that were 2.2- to 4.9-fold higher in cases of gastric cancer than in healthy volunteers. We also newly collected non-cancerous gastric mucosae of patients with a single gastric cancer and those with multiple gastric cancers. Patients in the latter group, who were considered to have a higher risk of gastric cancers [26], had a significantly higher $F L N c$ methylation level than patients with a single gastric cancer $(P<0.01, t$ test $)$ [27]. These results strongly indicate that methylation levels in non-cancerous gastric mucosae are a good candidate biomarker for gastric cancer risk. In order to confirm their clinical usefulness, a prospective study is currently being planned.

Methylation of specific genes in gastric mucosae by $H$. pylori infection, and its promising potential

In the initial study where eight regions of seven genes were analyzed [22], all eight regions were methylated in the presence of $H$. pylori infection. There are two possibilities explaining this result: (1) these eight regions are regions that can be methylated in gastric cancers, or (2) $\mathrm{H}$. pylori infection induces genome-wide, non-specific methylation of CGIs. To distinguish between these two possibilities, we analyzed the methylation of 48 genes in gastric mucosae of individuals with and without $H$. pylori infection. These 48 genes were selected because they can be methylation silenced in gastric cancer cell lines [14]. Some genes were resistant to methylation induction, and some were consistently methylated in individuals with $H$. pylori infection (unpublished data; for review, see [28]. Since low transcription levels are known to trigger promoter methylation [12, 29], it was concluded that $H$. pylori infection can induce decreased transcription of specific genes and that some of these can be methylated. This concept can be expanded to one in which some carcinogenic factors have the potential to induce methylation of specific genes in non-cancerous tissues and that the specific methylation profile of an individual can be used as a marker for past exposure to specific carcinogenic factors.

\section{Epigenetic field for cancerization}

The finding that methylation levels in non-cancerous gastric mucosae correlate with gastric cancer risk has the potential to be generalized to cancers of other tissues. Since this finding is closely related with the concept of field defect, or field for cancerization, which has a long history, we first provide a short review of the concept of field for cancerization and then discuss "epigenetic field for cancerization".

\section{The concept of field for cancerization}

The concept of "field for cancerization" was first used by Slaughter et al. in 1953 for describing oral cavity cancer [30] and was based on the phenomenon that, even after curative resection of a primary cancer, metachronous (secondary multiple) primary cancers developed further. This occurrence indicated that the background mucosae of a cancer patient were already predisposed to cancer development, providing a field for cancerization. In recent decades, the concept has been applied to cancers of many other organs, especially squamous cell carcinomas of the head and neck (HNSCC) [31, 32], squamous cell carcinomas of the esophagus [33, 34], adenocarcinomas from the Barrett's esophagus [35], stomach cancers [36], breast cancers [37], and skin cancers [38]. The presence of cells with mutations of tumor-related genes, such as $p 53$, in the field for cancerization has been shown for head and neck cancers $(21-52 \%)[31,32]$ and skin cancers (5/8) [38].

\section{Epigenetic field for cancerization}

As the deep involvement of aberrant DNA methylation in human cancers became clear, the occasional presence of aberrant DNA methylation in non-cancerous tissues was recognized in the colon [39, 40], liver [41], Barrett's esophagus [42], and stomach [43]. The presence of aberrant methylation in non-cancerous tissues suggested the involvement of the former in the field for cancerization. However, since DNA methylation can show non-significant fluctuation, analysis of control non-predisposed tissues 
from healthy individuals (or patients with cancers at other sites) is essential to demonstrate the association between DNA methylation and the field for cancerization. This was first achieved in the liver [41] and subsequently in the colon [44], stomach [22], and breasts ([45]; Table 1). Our study of the stomach is characterized by a marked difference achieved by quantitative methylation analysis and by the clear presence of an inducing factor, $H$. pylori, in addition to the systemic collection of non-predisposed tissues. These reports from multiple institutions strongly support the existence of an "epigenetic field for cancerization" in addition to a genetic field for cancerization.

Advantages of DNA methylation as a marker for a field for cancerization

There are several advantages to using DNA methylation as a marker of a field of cancerization. First, for some cancers, such as gastric cancers, aberrant DNA methylation of tumor-suppressor genes is more commonly observed than mutations [19]. In such cancers, an epigenetic field for cancerization is likely to be present and can be detected using appropriate marker genes. Second, the fractions of cells with aberrant methylation of marker genes can be much larger than those with mutations. In the case of noncancerous gastric mucosae of human gastric cancers, the former were in the range of $10^{-3}-10^{-1}$ [22, 27]. In contrast, the fractions of cells with mutations of a LacI marker gene were in the range of $10^{-4}-10^{-3}$ in the colon and liver of mice heavily exposed to a carcinogen [46]. Third, novel marker genes can be easily isolated because techniques for genome-wide screening for changes in DNA methylation are now available [12]. An ideal marker gene should be methylated in association with methylation of tumor- suppressor genes, but at much higher frequencies (Fig. 3). Finally, methylated DNA molecules can be precisely quantified, even when present at a frequency of $1 \times 10^{-3}$ [22]. For an assessment of the cancer risk in an individual, plus-minus judgment has limited meaning, and quantitative analysis is essential. Using qMSP of biopsy materials, we were able to predict the gastric cancer risk of individuals.

Inducing factors of aberrant DNA methylation and their detection

Helicobacter pylori was involved in the induction of the field for gastric cancers. Infection by $H$. pylori is known to induce severe chronic inflammation. Chronic inflammation is also present in ulcerative colitis for colon cancers, chronic hepatitis for liver cancers, and Barrett's esophagus for esophagus adenocarcinomas. Therefore, chronic inflammation, possibly specific types, is likely to induce aberrant DNA methylation in normal tissues and thus form a field for cancerization. Interestingly, interleukin 6 , whose polymorphisms are involved in the susceptibility of various cancers, is known to induce expression and activity of DNA methyltransferase [18]. Further investigations are necessary to clarify which cytokines are really involved.

\section{Epilogue}

The presence of an epigenetic field for cancerization, induced by $H$. pylori infection, is now evident for human gastric cancers. For gastric cancer patients with $H$. pylori infection, we fortunately have a realistic choice: eradication therapy for $H$. pylori. This will prevent further
Table 1 Reports on epigenetic field for cancerization (modified from [53]

UC, Ulcerative colitis; HBV, hepatitis B virus; $\mathrm{HCV}$, hepatitis $\mathrm{C}$ virus

\begin{tabular}{|c|c|c|c|}
\hline Cancer & Inducing factor & Analyzed gene & References \\
\hline Liver & $\mathrm{HBV}$ and/or $\mathrm{HCV}$ & $\begin{array}{l}C D K N 2 A, h M L H 1, T H B S-1 \\
\text { and five MINT loci }\end{array}$ & Kondo et al. [41] \\
\hline \multicolumn{4}{|l|}{ Colorectal cancer } \\
\hline Sporadic & Unknown & $M G M T$ & Shen et al. [44] \\
\hline UC associated & $\mathrm{UC}$ & $C D K N 2 A$ & Hsieh et al. [40] \\
\hline UC associated & $\mathrm{UC}$ & $E R, M Y O D, C D K N 2 A$, and $C S P G 2$ & Issa et al. [52] \\
\hline Barrett's cancer & Barrett's esophagus & $A P C, C D K N 2 A$, and $E S R 1$ & Eads et al. [48] \\
\hline Lung cancer & Smoking? & $\begin{array}{l}C D K N 2 A, M G M T, D A P K, S O C S 1, \\
R A S S F 1 A, C O X 2, \text { and } R A R \beta\end{array}$ & Guo et al. [49] \\
\hline Gastric cancer & H. pylori & $\begin{array}{l}C D K N 2 A, L O X, T H B D \\
H R A S L S, F L N c, H A N D 1 \\
\text { and } p 41 A R C\end{array}$ & Maekita et al. [22] \\
\hline Breast cancer & Unknown & CYP26A1 & Yan et al. [45] \\
\hline Renal cancer & Unknown & $\begin{array}{l}C D K N 2 A, h M L H 1, T H B S-1, \\
\text { and five MINT loci }\end{array}$ & Arai et al. [47] \\
\hline
\end{tabular}


exacerbation of an epigenetic field for cancerization and also enable us to measure the risk of metachronous gastric cancers accurately. Follow-up procedures will be modified depending upon the risk. Even if a high risk has already accumulated, there is a possibility that demethylating therapy could reduce the risk. If this scenario is eventually A

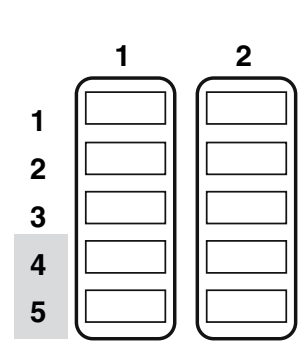

\section{Cell}
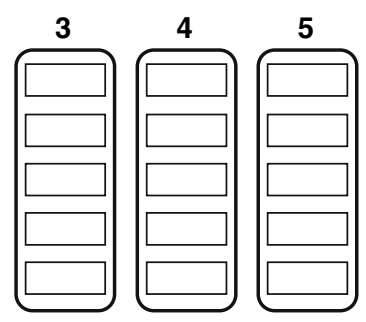

Exposure to carcinogenic factor

B
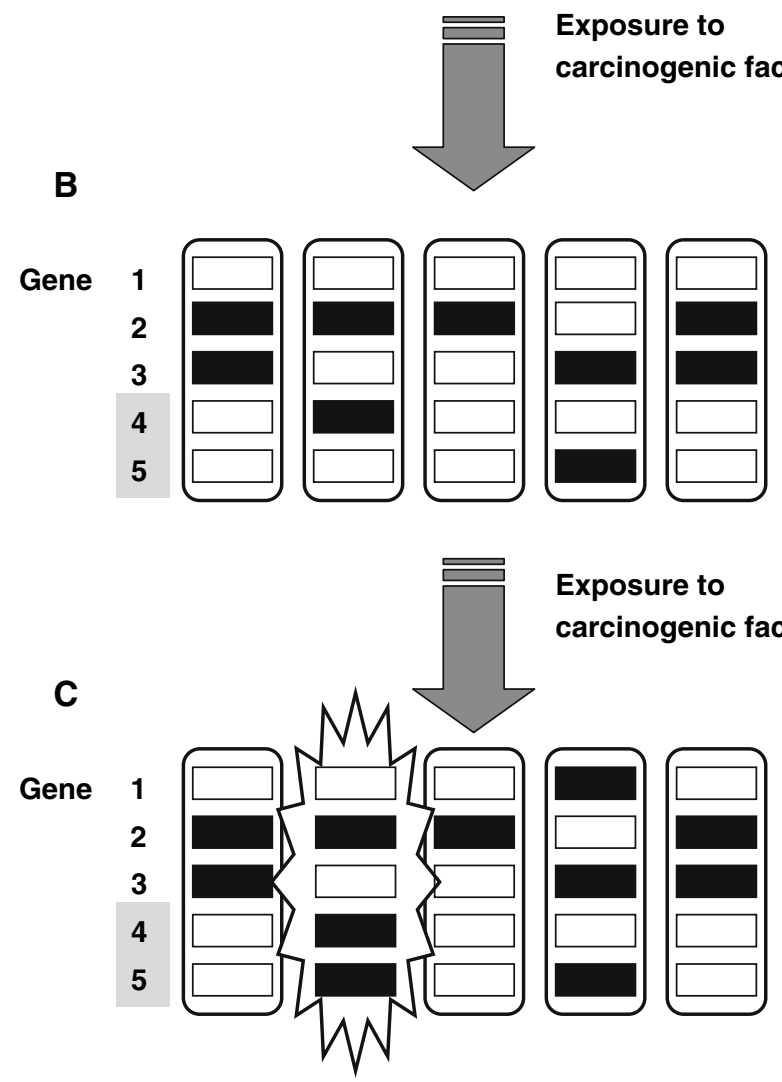

Fig. 3 Gene function and a good marker gene. Genes 4 and 5 are tumor-suppressor genes and, when both are methylated, cell transformation takes place. a In a normal tissue, no or little methylation is present. b After exposure to a carcinogenic factor, such as chronic inflammation, specific genes become methylated. Good marker genes (genes 2 and 3) are those readily methylated upon exposure to the carcinogenic factor in association with the methylation of tumorsuppressor genes, which are generally resistant to methylation. Specific methylation of genes 2 and 3, not gene 1, is a candidate marker for exposure to the carcinogenic factor. c After repeated exposure to the carcinogenic factor, the fractions of cells with methylated marker genes increase, and some cells (cell no. 2) can acquire methylation of multiple tumor-suppressor genes and transform realized, clinical management of gastric cancers will experience a great change.

The concept of epigenetic field cancerization also seems to be valid for colon and breast cancers [44, 45] and, possibly, for liver cancers, esophageal adenocarcinomas, lung cancers, and renal cancers [41, 47-49]. Since the involvement of epigenetic alterations seems not to be limited to cancers $[50,51]$, there is even a possibility that an epigenetic field defect could be identified for various diseases. It is clear that if disease risk at a time point can be measured by a DNA methylation marker, it will help people to change their lifestyles for more intensive disease prevention.

The clarification of just how much individual carcinogenic factors can contribute to human cancers is an important issue in public health. It is known that some carcinogenic factors leave their fingerprint in the tissues damaged by them - even if they themselves are no longer present - as specific DNA methylation patterns. If more fingerprints could be identified that are as distinct as that left by $H$. pylori, these could be used to identify carcinogenic factors involved in individual cancers. This would enable the appropriate efforts and resources to be focused on the elimination of carcinogenic factors at both individual and public levels.

Research in epigenetics is now very active world-wide. Sweeping changes in the clinical management of cancer patients and elimination procedures of carcinogenic factors are in sight.

\section{References}

1. Baylin SB, Ohm JE. Epigenetic gene silencing in cancer - a mechanism for early oncogenic pathway addiction? Nat Rev Cancer. 2006;6:107-16.

2. Ushijima T, Watanabe N, Okochi E, Kaneda A, Sugimura T, Miyamoto K. Fidelity of the methylation pattern, its variation in the genome. Genome Res. 2003;13:868-74.

3. Riggs AD, Xiong Z. Methylation and epigenetic fidelity. Proc Natl Acad Sci USA. 2004;101:4-5.

4. Bird A. DNA methylation patterns and epigenetic memory. Genes Dev. 2002;16:6-21.

5. Li E. Chromatin modification and epigenetic reprogramming in mammalian development. Nat Rev Genet. 2002;3:662-73.

6. Murayama A, Sakura K, Nakama M, Yasuzawa-Tanaka K, Fujita $\mathrm{E}$, Tateishi $\mathrm{Y}$, et al. A specific $\mathrm{CpG}$ site demethylation in the human interleukin 2 gene promoter is an epigenetic memory. EMBO J. 2006;25:1081-92.

7. Weaver IC, Cervoni N, Champagne FA, D'Alessio AC, Sharma $\mathrm{S}$, Seckl JR, et al. Epigenetic programming by maternal behavior. Nat Neurosci. 2004;7:847-54.

8. Feinberg AP, Tycko B. The history of cancer epigenetics. Nat Rev Cancer. 2004;4:143-53.

9. Kaneda A, Tsukamoto T, Takamura-Enya T, Watanabe N, Kaminishi M, Sugimura T, et al. Frequent hypomethylation in multiple promoter $\mathrm{CpG}$ islands is associated with global 
hypomethylation, but not with frequent promoter hypermethylation. Cancer Sci. 2004;95:58-64.

10. Gaudet F, Hodgson JG, Eden A, Jackson-Grusby L, Dausman J, Gray JW, et al. Induction of tumors in mice by genomic hypomethylation. Science. 2003;300:489-92.

11. De Smet C, Lurquin C, Lethe B, Martelange V, Boon T. DNA methylation is the primary silencing mechanism for a set of germ line- and tumor-specific genes with a CpG-rich promoter. Mol Cell Biol. 1999;19:7327-35.

12. Ushijima T. Detection and interpretation of altered methylation patterns in cancer cells. Nat Rev Cancer. 2005;5:223-31.

13. Weber M, Davies JJ, Wittig D, Oakeley EJ, Haase M, Lam WL, et al. Chromosome-wide and promoter-specific analyses identify sites of differential DNA methylation in normal and transformed human cells. Nat Genet. 2005;37:853-62.

14. Yamashita S, Tsujino Y, Moriguchi K, Tatematsu M, Ushijima T. Chemical genomic screening for methylation-silenced genes in gastric cancer cell lines using 5-aza-2'-deoxycytidine treatment and oligonucleotide microarray. Cancer Sci. 2006;97:64-71.

15. Miyamoto K, Ushijima T. Diagnostic and therapeutic applications of epigenetics. Jpn J Clin Oncol. 2005;35:293-301.

16. Weisenberger DJ, Siegmund KD, Campan M, Young J, Long TI, Faasse MA, et al. CpG island methylator phenotype underlies sporadic microsatellite instability and is tightly associated with BRAF mutation in colorectal cancer. Nat Genet. 2006;38:787-93.

17. Abe M, Ohira M, Kaneda A, Yagi Y, Yamamoto S, Kitano Y, et al. $\mathrm{CpG}$ island methylator phenotype is a strong determinant of poor prognosis in neuroblastomas. Cancer Res. 2005;65:828-34.

18. Hodge DR, Xiao W, Clausen PA, Heidecker G, Szyf M, Farrar WL. Interleukin-6 regulation of the human DNA methyltransferase (HDNMT) gene in human erythroleukemia cells. J Biol Chem. 2001;276:39508-11.

19. Ushijima T, Sasako M. Focus on gastric cancer. Cancer Cell. 2004;5:121-5.

20. Kaneda A, Wakazono K, Tsukamoto T, Watanabe N, Yagi Y, Tatematsu M, et al. Lysyl oxidase is a tumor suppressor gene inactivated by methylation and loss of heterozygosity in human gastric cancers. Cancer Res. 2004;64:6410-5.

21. Kaneda A, Kaminishi M, Yanagihara K, Sugimura T, Ushijima T. Identification of silencing of nine genes in human gastric cancers. Cancer Res. 2002;62:6645-50.

22. Maekita T, Nakazawa K, Mihara M, Nakajima T, Yanaoka K, Iguchi $\mathrm{M}$, et al. High levels of aberrant DNA methylation in Helicobacter pylori-infected gastric mucosae and its possible association with gastric cancer risk. Clin Cancer Res. 2006;12:989-95.

23. Ekstrom AM, Held M, Hansson LE, Engstrand L, Nyren O. Helicobacter pylori in gastric cancer established by CagA immunoblot as a marker of past infection. Gastroenterology. 2001;121:784-91.

24. Uemura N, Okamoto S, Yamamoto S, Matsumura N, Yamaguchi $\mathrm{S}$, Yamakido $\mathrm{M}$, et al. Helicobacter pylori infection and the development of gastric cancer. N Engl J Med. 2001;345:784-9.

25. Tatematsu M, Tsukamoto T, Inada K. Stem cells and gastric cancer: role of gastric and intestinal mixed intestinal metaplasia. Cancer Sci. 2003;94:135-41.

26. Nakajima T, Oda I, Gotoda T, Hamanaka H, Eguchi T, Yokoi C, et al. Metachronous gastric cancers after endoscopic resection: how effective is annual endoscopic surveillance? Gastric Cancer. 2006;9:93-8.

27. Nakajima T, Maekita T, Oda I, Gotoda T, Yamamoto S, Umemura $\mathrm{S}$, et al. Higher methylation levels in gastric mucosae significantly correlate with higher risk of gastric cancers. Cancer Epidemiol Biomark Prev. 2006;15:2317-21.

28. Ushijima T, Nakajima T, Maekita T. DNA methylation as a marker for the past and future. J Gastroenterol. 2006;41:401-7.
29. Ushijima T, Okochi-Takada E. Aberrant methylations in cancer cells: Where do they come from? Cancer Sci. 2005;96:206-11.

30. Slaughter DP, Southwick HW, Smejkal W. Field cancerization in oral stratified squamous epithelium; clinical implications of multicentric origin. Cancer. 1953;6:963-8.

31. Brennan JA, Mao L, Hruban RH, Boyle JO, Eby YJ, Koch WM, et al. Molecular assessment of histopathological staging in squamous-cell carcinoma of the head and neck. N Engl J Med. 1995;332:429-35.

32. Tabor MP, Brakenhoff RH, van Houten VM, Kummer JA, Snel MH, Snijders PJ, et al. Persistence of genetically altered fields in head and neck cancer patients: biological and clinical implications. Clin Cancer Res. 2001;7:1523-32.

33. Muto M, Nakane M, Hitomi Y, Yoshida S, Sasaki S, Ohtsu A, et al. Association between aldehyde dehydrogenase gene polymorphisms and the phenomenon of field cancerization in patients with head and neck cancer. Carcinogenesis. 2002;23:1759-65.

34. Braakhuis BJ, Tabor MP, Kummer JA, Leemans CR, Brakenhoff RH. A genetic explanation of Slaughter's concept of field cancerization: evidence and clinical implications. Cancer Res. 2003;63:1727-30.

35. Barrett MT, Sanchez CA, Prevo LJ, Wong DJ, Galipeau PC, Paulson TG, et al. Evolution of neoplastic cell lineages in Barrett oesophagus. Nat Genet. 1999;22:106-9.

36. Kang GH, Kim CJ, Kim WH, Kang YK, Kim HO, Kim YI. Genetic evidence for the multicentric origin of synchronous multiple gastric carcinoma. Lab Invest. 1997;76:407-17.

37. Heaphy CM, Bisoffi M, Fordyce CA, Haaland CM, Hines WC, Joste NE, et al. Telomere DNA content and allelic imbalance demonstrate field cancerization in histologically normal tissue adjacent to breast tumors. Int J Cancer. 2006;119:108-16.

38. Kanjilal S, Strom SS, Clayman GL, Weber RS, el-Naggar AK, Kapur V, et al. p53 mutations in nonmelanoma skin cancer of the head and neck: molecular evidence for field cancerization. Cancer Res. 1995;55:3604-9.

39. Issa JP, Ottaviano YL, Celano P, Hamilton SR, Davidson NE, Baylin SB. Methylation of the oestrogen receptor $\mathrm{CpG}$ island links ageing and neoplasia in human colon. Nat Genet. 1994;7:536-40.

40. Hsieh CJ, Klump B, Holzmann K, Borchard F, Gregor M, Porschen R. Hypermethylation of the p16INK4a promoter in colectomy specimens of patients with long-standing and extensive ulcerative colitis. Cancer Res. 1998;58:3942-5.

41. Kondo Y, Kanai Y, Sakamoto M, Mizokami M, Ueda R, Hirohashi S. Genetic instability and aberrant DNA methylation in chronic hepatitis and cirrhosis - A comprehensive study of loss of heterozygosity and microsatellite instability at 39 loci and DNA hypermethylation on $8 \mathrm{CpG}$ islands in microdissected specimens from patients with hepatocellular carcinoma. Hepatology. 2000;32:970-9.

42. Eads CA, Lord RV, Wickramasinghe K, Long TI, Kurumboor SK, Bernstein L, et al. Epigenetic patterns in the progression of esophageal adenocarcinoma. Cancer Res. 2001;61:3410-8.

43. Waki T, Tamura G, Tsuchiya T, Sato K, Nishizuka S, Motoyama T. Promoter methylation status of E-cadherin, hMLH1, and p16 genes in nonneoplastic gastric epithelia. Am J Pathol. 2002;161:399-403.

44. Shen L, Kondo Y, Rosner GL, Xiao L, Hernandez NS, Vilaythong $\mathrm{J}$, et al. MGMT promoter methylation and field defect in sporadic colorectal cancer. J Natl Cancer Inst. 2005;97:1330-8.

45. Yan PS, Venkataramu C, Ibrahim A, Liu JC, Shen RZ, Diaz NM, et al. Mapping geographic zones of cancer risk with epigenetic biomarkers in normal breast tissue. Clin Cancer Res. 2006;12:6626-36.

46. Nagao M, Ochiai M, Okochi E, Ushijima T, Sugimura T. LacI transgenic animal study: relationships among DNA-adduct levels, 
mutant frequencies and cancer incidences. Mutat Res. 2001;477:119-24.

47. Arai E, Kanai Y, Ushijima S, Fujimoto H, Mukai K, Hirohashi S. Regional DNA hypermethylation and DNA methyltransferase (DNMT) 1 protein overexpression in both renal tumors and corresponding nontumorous renal tissues. Int $\mathrm{J}$ Cancer. 2006;119:288-96.

48. Eads CA, Lord RV, Kurumboor SK, Wickramasinghe K, Skinner ML, Long TI, et al. Fields of aberrant CpG island hypermethylation in Barrett's esophagus and associated adenocarcinoma. Cancer Res. 2000;60:5021-6.

49. Guo M, House MG, Hooker C, Han Y, Heath E, Gabrielson E, et al. Promoter hypermethylation of resected bronchial margins: a field defect of changes? Clin Cancer Res. 2004;10:5131-6.
50. Robertson KD. DNA methylation and human disease. Nat Rev Genet. 2005;6:597-610.

51. Mihara M, Yoshida Y, Tsukamoto T, Inada K, Nakanishi Y, Yagi $\mathrm{Y}$, et al. Methylation of multiple genes in gastric glands with intestinal metaplasia: A disorder with polyclonal origins. Am J Pathol. 2006;169:1643-51.

52. Issa JP, Ahuja N, Toyota M, Bronner MP, Brentnall TA. Accelerated age-related $\mathrm{CpG}$ island methylation in ulcerative colitis. Cancer Res. 2001;61:3573-7.

53. Ushijima T. Epigenetic field for cancerization. J Biochem Mol Biol. 2007;40:142-50. 